\title{
Repair of an avulsed upper lid and partially severed lower lid
}

\author{
G W AYLWARD AND R OHRI \\ From the Western Ophthalmic Hospital, Marylebone Road, London NW1 5YE
}

SUMMARY We present a case in which trauma from a broken glass resulted in complete amputation of the upper lid and severe lacerations to the lower lid but with an intact and functioning globe. The avulsed upper lid was repaired as a composite autograft. The possible management of such an unusual case is discussed.

\section{Case report}

A 45-year-old man presented to the Western Ophthalmic Hospital after being assaulted one hour previously in a public house with a broken beer glass. On examination he was found to have multiple lacerations of the forehead and tissues surrounding the right eye. There was a full-thickness defect of the right upper lid involving almost its entire length with a small remnant of margin remaining at the medial and lateral extremities. The defect extended vertically to beyond the upper skin crease, exposing the cornea and sclera to $10 \mathrm{~mm}$ from the limbus (Fig. 1).

The missing lid tissue had been recovered intact from the beer glass by the ambulance crew and accompanied the patient in a brown envelope (Fig. 2). There were two full thickness lacerations of the lower lid. One was just medial to the punctum involving the lower canaliculus and extended vertically for $10 \mathrm{~mm}$ from the lid margin. The other was $3 \mathrm{~mm}$ medial to the lateral canthus and extended $10 \mathrm{~mm}$ vertically from the lid margin. This resulted in an extensive flap of intermediate lid tissue which was lying reflected on the cheek exposing the lower fornix. A visual acuity of $6 / 18$ was recorded from the right eye. The cornea was clear and, remarkably, there was no laceration of the globe.

In view of the large defect and consequent exposure of the cornea it was decided to undertake a primary repair using the accompanying lid tissue as a composite autograft. The patient was started on systemic ampicillin $500 \mathrm{mg}$ four times a day, and the severed lid was wrapped in a sterile swab moistened

Correspondence to Miss R Ohri, Western Ophthalmic Hospital, Marylebone Road, London NW1 5 YE. with normal saline and refrigerated. The lower lid flap was brought up to cover the cornea and taped to the brow.

The patient was taken to the theatre four hours later and given a general anaesthetic. The lid tissue was found to fit the defect in the upper lid exactly. It was sutured into place in layers with interrupted $6 / 0$ collagen sutures to the conjunctiva and subcutaneous tissues, and $6 / 0$ black silk to the skin. The lower lid flap was aligned to the free edges and repaired in layers with the same suture materials. The repair of the margin was performed under the operating microscope. No attempt was made to anastomose the severed ends of the canaliculus. Full examination of the globe revealed a small laceration in the lower conjunctiva, but the underlying sclera was intact. There was no intraocular injury apart from a small area of commotio retinae at 6 o'clock. Chloramphenicol ointment was instilled and a firm pad and bandage applied for $\mathbf{4 8}$ hours.

Postoperatively the repair looked satisfactory and

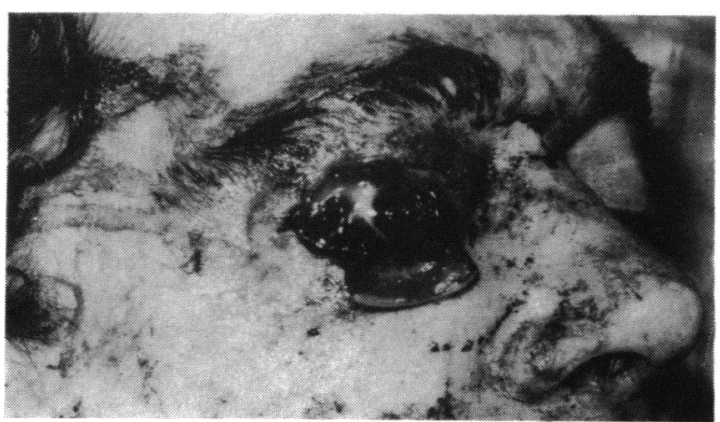

Fig. 1 Preoperative appearance of the right eye showing the absence of the upper lid and the severely damaged lower lid. 
Fig. 2 The segment of upper lid prior to the autograft.

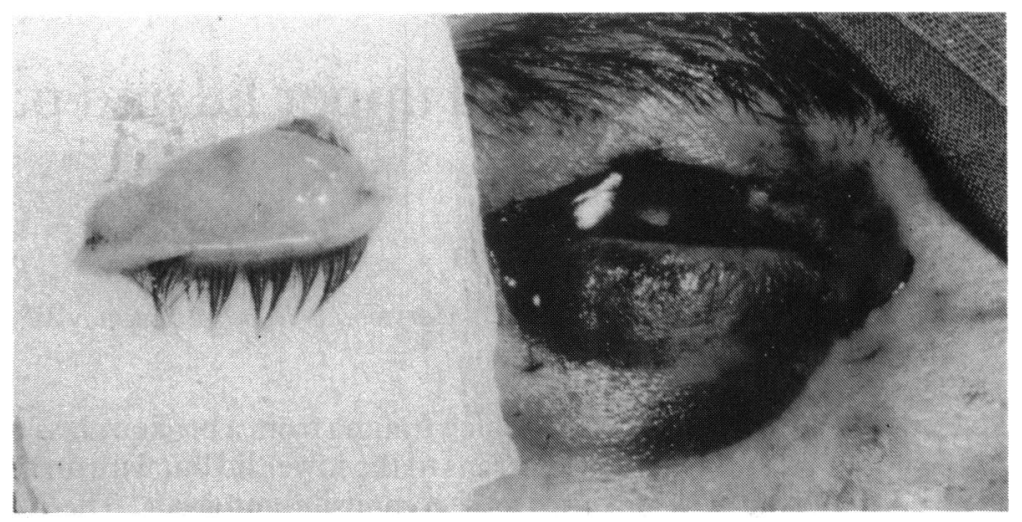

able upper lid function with no signs of corneal exposure. The appearance of the lower lid represents a cosmetic problem to the patient, and further surgery is planned to correct this.

\section{Discussion}

The problems associated with the reconstruction of the upper lid are well described by Mustardé. ${ }^{1}$ His recommended method for repair of large defects makes use of a portion of lower lid on a vascular pedicle. The Cutler-Beard technique ${ }^{2}$ and the method of Hughes ${ }^{3}$ also make use of lower lid. In our case the lower lid was severely injured and the marginal circulation was compromised. We therefore considered that these techniques were not applicable. McGregor described a method using lateral advancement in conjunction with a Z-plasty to relieve tension. ${ }^{4}$ However, he recommends it for defects no larger than two thirds of the width of the lid and with portions of tarsal plate either side. A

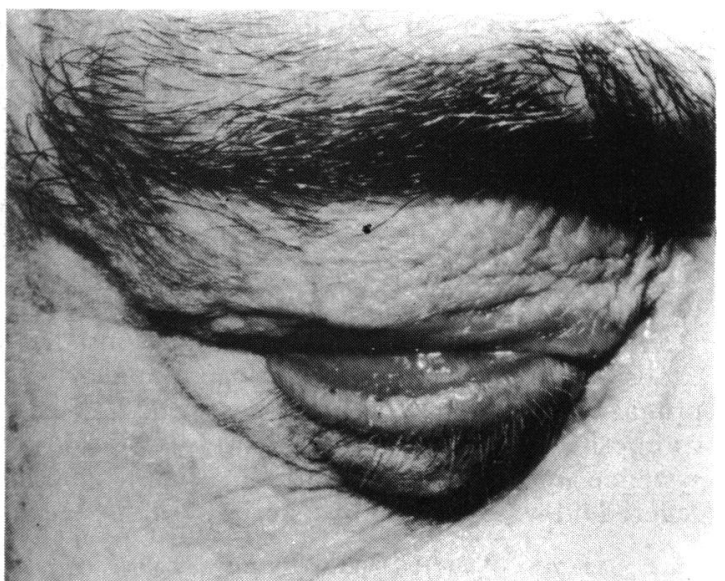

Fig. 4 One year after surgery; lids closed.
Fig. 3 One year after surgery; lids open. There is upper lid retraction and loss of cilia. The lower lid is thickened and there is ectropion. 
further technique was suggested by Mustardé ${ }^{1}$ as being suitable for the treatment of a case of total loss of both eyelids with an intact eye, though he had not actually seen such a case. It involves suturing conjunctival flaps across the cornea and covering with a midline flap from the forehead, dividing the graft to fashion two lids at a later date. This method was used in a case described by Hay, ${ }^{5}$ and similar techniques were used in two cases described by Achauer and Menick. ${ }^{6}$

We concluded that the simplest approach to the immediate management of this case was to suture the severed lid into place as a composite autograft. There was obviously a risk of necrosis, but there were several favourable factors. Firstly, the local blood supply is excellent in this region. Secondly the severed lid fitted the defect exactly, with no missing tissue, so that it could be sutured without tension. Thirdly, the edges appeared to be cleanly cut with minimal contusion. Fourthly the ischaemic time was only five hours, and for four of these the lid was kept moist and refrigerated.

In the event the graft appeared to take well, though there was subsequent loss of cilia and some lid retraction. These complications have been reported recently in a series of five cases of eyelid avulsion due to human bites. ${ }^{7}$ All five cases were treated in a similar manner to this case and no necrosis occurred even though one was grafted 26 hours after trauma. Two patients developed lid retraction and loss of cilia. However, this did not occur in those patients who underwent surgery less than 14 hours after trauma.

We thank Miss Sue Ford, of the Western Ophthalmic Hospital, who took and prepared the photographs, and Mr Redmond J H Smith for valuable advice and for allowing us to report on his patient.

\section{References}

1 Mustardé JC. Repair and reconstruction in the orbital region. 2nd ed. Edinburgh: Churchill Livingstone, 1980.

2 Cutler NL, Beard C. A method for partial and total upper lid reconstruction. Am J Ophthalmol 1955; 39: 1-7.

3 Hughes WL. Total reconstruction of the upper lid (blepharopoiesis). Am J Ophthalmol 1945; 28: 980-92.

$4 \mathrm{McGregor}$ IA. Eyelid reconstruction following subtotal resection of upper or lower lid. Br J Plast Surg 1973; 26: 346-54.

5 Hay D. Reconstruction of both eyelids following traumatic loss. Br J Plast Surg 1971; 24: 361-4.

6 Achauer BM, Menick FJ. Salvage of seeing eyes after avulsion of upper and lower lids. Plast Reconstr Surg 1985; 75: 11-5.

7 Spinelli HM, Sherman JE, Lisman RD, Smith B. Human bites of the eyelid. Plast Reconstr Surg 1986; 78: 610-4.

Accepted for publication 5 November 1987. 